\title{
BRIEF
}

\section{The Impact Of COVID-19 On Pharmacy Student Stress During High-Stakes, Performance-Based Assessments in Skills-Based Courses}

\author{
Katelyn N. Hettinger, PharmD, ${ }^{a}$ Chelsea M. Baker, PharmD, MBA, ${ }^{b}$ Megan E. Brelage, ${ }^{b}$ Hannah M. Smith, \\ PharmD, ${ }^{c}$ Jamie L. Woodyard, PharmD ${ }^{b}$ \\ ${ }^{a}$ Purdue University, College of Pharmacy, Indianapolis, Indiana \\ ${ }^{\mathrm{b}}$ Purdue University College of Pharmacy, West Lafayette, Indiana \\ ${ }^{c}$ Topeka Pharmacy, Topeka, Indiana
}

Corresponding Author: Jamie L. Woodyard, Purdue University, College of Pharmacy, 575 Stadium Mall Dr., RHPH 349, West Lafayette, IN 47907. Tel: 765-494-9642. Email: woodyard@ purdue.edu

Submitted August 30, 2021; accepted February 11, 2022; ePublished February 2022

Objective. To compare stress levels of pharmacy students in high-stakes, performance-based assessments (PBAs) administered during skills-based laboratory courses in normal classroom environments versus pandemic classroom environments impacted by COVID- 19 .

Methods. In 2019, prior to the start of the COVID-19 pandemic, Doctor of Pharmacy (PharmD) student stress levels were assessed via a voluntary, paper-based survey before and after PBAs. Students were given a modified version of this survey in 2020 during the pandemic. The 2019 and 2020 survey responses were compared utilizing Wilcoxon Rank Sum tests.

Results. Pharmacy students reported higher perceived stress levels before PBAs (3.78 vs. 3.45) and after PBAs (2.84 vs. 2.52) prior to the pandemic compared to amid pandemic. Students identified stress as negatively impacting their PBA performance in both years (3.42 vs. 3.1). Students had similar interest in wellness activities in both phases.

Conclusion. Colleges of Pharmacy should consider implementing stress relief programs around high-stakes assessments as well as prioritizing wellness initiatives within curricula.

Keywords: COVID-19, student stress, pharmacy students, assessments

\section{INTRODUCTION}

Students in Doctor of Pharmacy (PharmD) programs consistently have higher perceived stress than standard populations. ${ }^{1}$ Higher stress levels are associated with depression and anxiety, which in turn correlate to decreased empathy, lower mental health-related quality of life, and greater use of unhealthy coping mechanisms. ${ }^{1-4}$

Approximately $77 \%$ of students identify pressure to succeed as a major cause of stress. ${ }^{1}$ Other stressors include finances, concerns about future employment, and personal health. ${ }^{1-5}$ In 2017, the American Association of Colleges of Pharmacy (AACP) recommended pharmacy schools expand wellness efforts, urging colleges to make "providing support to students a priority." As a result, efforts to better understand and prevent student stress have become increasingly integrated into pharmacy programs. ${ }^{2,5}$

Current literature suggests students experience more stress during required "high-stakes" assessments. ${ }^{6-7}$ Scores on "high-stakes" assessments directly affect progression in the pharmacy curriculum and thus are utilized as validation exercises to assure students have achieved set learning objectives. ${ }^{6-12}$ The "high-stakes" learning environment is simulated to mimic the gravity of larger-scale examinations, such as the North American Pharmacist Licensure Examination (NAPLEX). ${ }^{8-9}$

Moreover, there are many unknowns as to the physiological and environmental impact of the COVID-19 pandemic on students' educational journeys. ${ }^{5}$ Xiong and colleagues reported increased levels of anxiety, depression, and post-traumatic stress disorder in general populations during the COVID-19 pandemic. Additionally, student status was associated with increased distress. ${ }^{13}$

Although some research regarding stress and the COVID-19 pandemic has been published, there is a paucity of data comparing overall stress of pharmacy students in the normal curricula versus in a pandemic-affected environment and how these changes will ultimately affect students and their professional success. ${ }^{5,13}$ With known increases in stress during PBAs, pandemic PBAs could result in even higher stress levels amongst students. ${ }^{6}$ This study addresses this gap in literature by disseminating a modified version of a survey in a pandemic-affected environment previously utilized to 
assess student stress in a normal classroom environment. This research could inform future wellness efforts made by pharmacy programs.

\section{METHODS}

A survey-based, dual phase design was utilized to assess first-through-third year (P1-P3) pharmacy students' perceived levels of stress during high-stakes, PBAs at Purdue University College of Pharmacy. A voluntary, anonymous paper-based survey was administered to students to assess their stress levels directly before and after PBAs in both 2019 (referred to as Phase One) and 2020 (referred to as Phase Two). All P1-P3 students at the time of each survey distribution period were eligible to participate. Whereas some students were enrolled in both Phase One and Phase Two, individual student data was unable to be linked.

PBAs take place within the skills laboratory curriculum, which consists of six, stand-alone, mandatory courses occurring each semester within the P1-P3 years of the PharmD program. Each course contains set PBA stations, and students must pass each station in order to pass the course and progress in the curriculum. P1 students are assessed on blood pressure, heart rate, and respiratory rate measurement of a standardized patient, compounding calculations, and head, eyes, ears, nose, throat self-care. P2 students are assessed on counseling skills for antihypertensive medications and diabetes devices, as well as problem prioritization using a teaching electronic medical record (tEMR). P3 students are assessed on problem prioritization and a patient case presentation utilizing the tEMR.

Phase One (Pre-Pandemic): The eight-item survey utilized in Phase One was developed with the intent to gain a better understanding of the perceived stress PharmD students experience directly before and after high-stakes PBAs. This survey included four five-point Likert-scale items. Two items evaluated perceived stress levels directly before and after PBAs with five indicating very high stress and one indicating no stress. One item assessed the impact of stress on PBA performance with five indicating very high impact and one indicating no impact. The fourth item assessed interest in participating in mindfulness activities prior to PBAs in the future with five indicating very high likeliness and one indicating not very likely.

The survey also included two open-ended response items asking students how they know they are personally stressed as well as how they alleviate stress related to PBAs specifically. Two additional open-ended items assessed student interest in mindfulness activities. Surveys were paper-based and disseminated over one week in October 2019 directly before and after PBAs during scheduled laboratory course times.

Phase Two (Amid-Pandemic): The Phase One surveys were modified for Phase Two to include demographic questions and the Cohen's Perceived Stress Scale (PSS-10) questionnaire. ${ }^{14,15}$ The PSS-10 is a validated survey instrument developed to assess perceived stress levels in the United States and has been widely used across the US as well as with pharmacy students. ${ }^{15,16,17}$ The Phase Two survey included a total of 21 items: the eight items described above in Phase One, three demographic questions (age, gender, and professional year), and the ten questions included in the PSS-10. The results from the PSS-10 will be described in a separate manuscript. Consistent with Phase One, Phase Two surveys were paper-based and disseminated over one week in October-November 2020 directly before and after PBAs.

For quantitative date, three comparisons were made. Wilcoxon Rank sum tests were utilized to compare the following independent populations: 1) Average perceived stress levels of pharmacy students overall in Phase One versus Phase Two during PBAs and 2) Average perceived stress levels of P1, P2, and P3 pharmacy students in Phase One versus Phase Two. For the final comparison, Wilcoxon signed rank tests were utilized to compare the paired Pre- and Post- PBA stress rating differences amongst $\mathrm{P} 1 \mathrm{~s}, \mathrm{P} 2 \mathrm{~s}$, and $\mathrm{P} 3 \mathrm{~s}$ in Phase One as well as Phase Two. An a priori alpha of 0.05 was utilized for all statistical tests. Open-ended survey item responses were independently reviewed by two researchers for common themes. Questions asked included "How do you know when you are stressed?" and "What, if anything, did you do to help alleviate your stress prior to PBAs?". Study approval was received by Purdue University's Institutional Review Board.

\section{RESULTS}

In Phase One of the study, 426 (94.7\%) P1-P3 PharmD students participated compared to 375 (84.2\%) students in Phase Two. Demographics of study participants in Phase Two can be found in Table 1.

Perceived stress levels of pharmacy students in Phase One versus Phase Two: In Phase One, students overall across all professional years reported an average pre-PBA perceived stress score of 3.78 compared to a 3.45 in Phase Two (Table 2). Students also reported significantly $(p<.05)$ lower stress scores post-PBA in both phases across all professional years. The average post-PBA perceived stress score in Phase One was 2.84 compared to 2.52 in Phase Two. In both phases, students noted stress as having a moderate-to-high impact, on average, on PBA performance. Only students in their P3 year reported stress levels as having a significantly negative impact on PBA performance $(p<.001)$. 
Pre- and Post-PBA stress rating differences amongst P1s, P2s, and P3s in Phase One and Phase Two: Post-PBA stress in Phase Two was significantly less than in the Phase One cohort for P1s and P2s but not for P3s $(p=.22)$. All students, across both phases and all professional years, experienced a significant decrease in perceived stress directly after their PBAs compared to directly before. The pre-post difference in perceived stress between Phase One and Phase Two was not found to be significant for any professional year (Table 3).

Additionally, student interest in de-stressing activities before and/or after PBAs was assessed. In Phase One, 288 (68\%) of participants and 213 (59\%) of respondents in Phase Two expressed interest in de-stressing mindfulness activities before and/or after PBAs. A few students expressed perceived value in de-stressing activities in general but preferred to spend time practicing on their own rather than participating in wellness activities. Activities students expressed the most interest in included mediation (32-33\%) and deep breathing (40-41\%). Students expressed similar interest in coloring, games, and light stretching across both years (19-25\%).

\section{DISCUSSION}

In contrast to our hypothesis, respondents' perceived stress levels were on average lower before and after PBAs in Phase Two versus Phase One. Several factors may have contributed to this. Consistent with AACP recommendations, Purdue University College of Pharmacy hired a Wellness Officer in 2020 to further integrate wellness activities into the curriculum. ${ }^{5}$ Additionally, student wellness ambassadors appointed to each professional class stimulated positive discussion regarding health and wellness through weekly emails and social media engagement. Overcoming stress was a prominent focus among the entire College during the 2020-2021 academic year.

The restructuring of skills-based courses and partial virtual aspect due to the pandemic may have also had an effect on perceived stress levels. Due to the absence of all school-wide breaks, students gained an additional week of class time that was utilized for PBA practice in 2020. In Phase One of the study, several students noted additional practice would help them feel more prepared and thus decrease their stress, and in 2020 students gained this additional practice opportunity organically. Furthermore, the in-person instructional time of most labs was decreased from 3 hours to 1.5 hours in Fall 2020. This change was made in order to accommodate social distancing guidelines. Students wore masks at all times and face shields when actively engaging in activities with other students or lab instructors. Whereas all students were in-person for PBAs, in some cases their evaluators were virtual. The modified length of labs conducted in-person could have de-escalated students' stress as students now had increased autonomy over their time, allowing for more time to practice. Of note, the PBA length was not modified in Phase Two despite other changes due to COVID-19.

Previous literature confirms increased perceived stress of pharmacy students ${ }^{1-5,17}$, yet minimal literature regarding perceived stress levels in a customarily stressed student population during a pandemic has yet been published. A limitation of this study includes the lack of data for P2 students in 2019 and 2020. This class had significantly less participation in the perceived stress pre- and post- surveys for unknown reasons. The addition of the PSS-10 and demographic questions increased the length of the survey in Phase Two and may have contributed to an overall lower response rate. Another limitation is pharmacy students surveyed were from one college of pharmacy and these findings may not be generalizable to pharmacy students at different schools.

Due to the nature of a global pandemic, students have endured unexpected changes and overcome new challenges. Some of these could include, but are not limited to, family members becoming infected with COVID-19, changes to school structure, finances and/or job security. How students perceive stress associated with PBAs may have decreased in Phase Two due to perspective new stressors and factors that took precedence in their lives because of COVID- 19. Although students reported reduced stress levels in 2020 compared to 2019, students still report stress and acknowledge its impact on their PBA performance. An increased emphasis on wellness should be a focus in PharmD curriculums.

Previous literature supports the implementation of stress relief activities such as yoga, mindfulness, and coloring. ${ }^{18} \mathrm{~A}$ majority of students in this study noted interest in participating in similar wellness activities. Additional examples of activities from Sclesselman and colleagues include: virtual group exercises, podcast sharing, virtual town halls and email check-ins, pharmacy telehealth, and senior center check-ins. ${ }^{5}$ Continued emphasis on wellness in the PharmD curriculum will positively impact pharmacists well into their professional career.

Areas of future research include exploring the results of the PSS-10 in this study to examine trends in perceived stress levels in pharmacy students' mid-pandemic. Additionally, the effect of attending university during a pandemic should be studied to address potential mental health implications in young pharmacists. ${ }^{19}$

\section{CONCLUSION}

Students reported significantly lower stress levels in regard to PBAs during the COVID-19 pandemic compared to PBAs in non-pandemic conditions. Increased wellness efforts during this time may have contributed to lower stress levels. 
However, students still report stress and expressed similar interest in de-stressing and wellness activities before PBAs mid-pandemic. Based on the results of this study, Colleges of Pharmacy should consider implementing stress relief programs around high-stakes assessments as well as prioritizing wellness initiatives within their curricula.

\section{ACKNOWLEDGEMENTS}

The authors would like to thank Dr. Margie Snyder for her continued guidance and review and Kevin LaMaster and Zeyu Zhang for their statistical analysis contributions.

\section{REFERENCES}

1. Garber MC, Huston SA, Breese CR. Sources of stress in a pharmacy student population. Curr Pharm Teach Learn. 2019;11(4):329-337. doi:10.1016/j.cptl.2019.01.014

2. Hirsch JD, Nemlekar P, Phuong P, et al. Patterns of Stress, Coping and Health-Related Quality of Life in Doctor of Pharmacy Students. Am J Pharm Educ. 2020;84(3):7547. doi:10.5688/ajpe7547

3. Marshall LL, Allison A, Nykamp D, Lanke S. Perceived stress and quality of life among doctor of pharmacy students. Am J Pharm Educ. 2008;72(6):137. doi:10.5688/aj7206137

4. Votta RJ, Benau EM. Predictors of Stress in doctor of pharmacy students: Results from a nationwide survey. Curr Pharm Teach Learn. 2013;5(5):365-372. doi:10.1016/j.cptl.2013.06.014.

5. Schlesselman LS, Cain J, DiVall M. Improving and restoring the well-being and resilience of pharmacy students during a pandemic. Am J Pharm Educ. 2020;84(6):677-682 doi:10.5688/ajpe8144

6. Longyhore DL. Pharmacy student anxiety and success with objective structured clinical examinations. Am J Pharm Educ. 2017;81(1);7. doi:10.5688/ajpe8117

7. Attali Y. Effort in Low-stakes assessments: what does it take to perform as well as in a high-stakes setting? Educ Psychol Meas. 2016;76(6):1045-1058. doi:10.1177/0013164416634789

8. Peeters MJ, Cor MK. Guidance for high-stakes testing within pharmacy educational assessment. Curr Pharm Teach Learn. 2020;12(1):1-4. doi:10.1016/j.cptl.2019.10.001

9. Hunsicker J, Chitwood T. High-stakes testing in nursing education: a review of the literature. Nurse Educ. 2018;43(4):183-186. doi:10.1097/NNE.0000000000000475

10. Gortney J, Rudolph MJ, Augustine JM, et al. National trends in the adoption of pharmacy curriculum outcomes assessment for student assessment and remediation. Am J Pharm Educ. 2019;83(6):6796. doi:10.5688/ajpe6796

11. McDonough SL, Kleppinger EL, Donaldson AR, et al. Going "high stakes" with a pharmacy OSCE: Lessons learned in the transition. Curr Pharm Teach Learn. 2015;7(1):4-11. doi:10.106/j.cptl.2014.09.017

12. Tanzer K, Dintzner M. Promoting professional socialization within the experiential curriculum: implementation of a high-stakes professionalism rubric. Am J Pharm Educ. 2017;81(1):19. doi:10.5688/ajpe81119

13. Xiong J, Lipsitz O, Nasri F, et al. Impact of COVID-19 pandemic on mental health in the general population: A systematic review. J Affect Disord. 2020; 277: 55-64. doi:10.1016/j.jad.2020.08.001

14. Cohen S, Kamarck T, Mermelstein R. A global measure of perceived Stress. J Health Soc Behav. 1983;24(4):38596.

15. Cohen S., Janicki-Deverts D. Who's Stressed? Distributions of Psychological Stress in the United States in Probability Samples from 1983, 2006, and 2009. J App Soc Psych. 2012;42(6):1320-1334. doi: 10.1111/j.15591816.2012.00900.x

16. Baik SH, Fox RS, Mills SD, et al. Reliability and Validity of the Perceived Stress Scale-10 in Hispanic Americans with English or Spanish language preference. J Health Psychol/ 2019;24(5):628-639. doi: $10.117 / 1359105316684938$

17. Spivey CA, Havrda D, Stallworth S, et al. Longitudinal examination of perceived stress and academic performance of first-year student pharmacists. Curr Pharm Teach Learn. 2020: 12(9): 1116-1122. doi: 10.1016/j.cptl.2020.05.002

18. Lemay V, Hoolahan J, Buchanan A. Impact of a yoga and meditation intervention on students' stress and anxiety levels. Am J Pharm Educ. 2019;83(5):7001. doi:10.5688/ajpe7001

19. Jones AM, Clark JS, Mohammad RA. Burnout and secondary traumatic stress in health-system pharmacists during the COVID-19 pandemic. Am J Health Syst Pharm. 2021;78(9):818-824. doi:10.1093/ajhp/zxab051 


\begin{tabular}{|c|c|c|c|}
\hline \multicolumn{4}{|c|}{$\begin{array}{l}\text { Table 1. Demographics of Participants in Phase Two of } \\
\text { in Skills-Based Courses During a Global Pandemic }\end{array}$} \\
\hline & $\mathrm{P} 1$ & $\mathrm{P} 2$ & P3 \\
\hline \multicolumn{4}{|l|}{ Gender $^{\# *}$} \\
\hline Female & $89(64)$ & $42(66)$ & 87 (69.6) \\
\hline Male & $49(35.3)$ & $21(33)$ & 37 (29.6) \\
\hline Gender variant non-conforming & 0 & 0 & $1(0.8)$ \\
\hline Prefer not to answer & $1(0.7)$ & $1(1.6)$ & 0 \\
\hline \multicolumn{4}{|l|}{ Age } \\
\hline $\mathrm{M}(\mathrm{SD})$ & $21.4(2.7)$ & $21.8(1.3)$ & $23(1.8)$ \\
\hline Range & $19-41$ & $21-27$ & $22-36$ \\
\hline \multicolumn{4}{|l|}{$\operatorname{Race}_{+}^{\#}$} \\
\hline American Indian or Alaska Native & $1(0.7)$ & 0 & 0 \\
\hline Asian & $41(29.5)$ & $15(23.4)$ & $14(11.2)$ \\
\hline Black or African American & $15(10.8)$ & $4(6.3)$ & $9(7.2)$ \\
\hline Hispanic, Latino, or Spanish & $5(3.6)$ & $2(3.1)$ & $7(5.6)$ \\
\hline Middle Eastern or North African & $4(2.9)$ & $2(3.1)$ & $3(2.4)$ \\
\hline Native Hawaiian or other Pacific Islander & $1(0.7)$ & 0 & 0 \\
\hline White & $96(69.1)$ & $41(64)$ & $94(75.2)$ \\
\hline Other & 0 & 0 & $1(0.8)$ \\
\hline Prefer not to answer & $2(1.4)$ & $3(4.7)$ & $1(0.8)$ \\
\hline
\end{tabular}

Abbreviations: $\mathrm{P} 1$ = first professional year, $\mathrm{P} 2=$ second professional year, $\mathrm{P} 3=$ third professional year

$\vec{b} \quad$ \#emographics for gender and race represented as $\mathrm{n}(\%)$. Not all students responded to demographic questions.

*Zero students identified as a transgender male or female. This option was omitted for this purpose from the demographic table

+ Students could identify as more than one race 
Table 2. Perceived Stress by Phase, Professional Year and Total

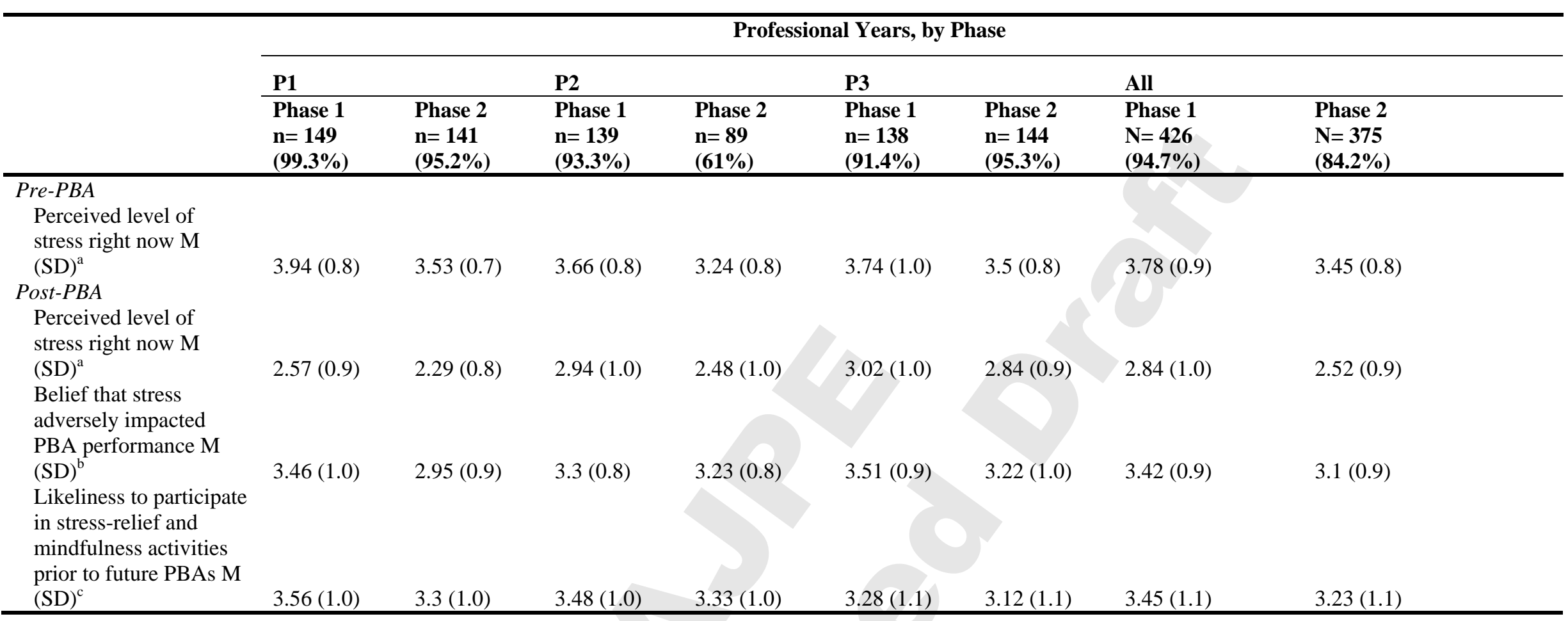

Abbreviations: $\mathrm{P} 1$ = first professional year, $\mathrm{P} 2=$ second professional year, $\mathrm{P} 3=$ third professional year

Percentages refer to response rate

${ }^{\text {a }}$ Response choices utilizing a 5-point Likert-type scale where $1=$ No Stress, $2=$ Low Stress, $3=$ Moderate Stress, $4=$ High Stress, $5=$ Very High Stress

${ }^{\mathrm{b}}$ Response choices utilizing a 5-point Likert-type scale where $1=$ No Impact, $2=$ Low Impact, $3=$ Moderate Impact, $4=$ High Impact, $5=$ Very High Impact

${ }^{\mathrm{c}}$ Response choices utilizing a 5-point Likert-type scale where $1=$ Not at all likely, $2=$ Not very likely, $3=$ Neutral, $4=$ Somewhat likely, $5=$ Very likely 
